\title{
Radicular cyst: Atypical presentation and therapeutic dilemma
}

SADJ September 2017, Vol 72 no 8 p379 - p382

S Tootla', V Premviyasa ${ }^{2}$, V Yengopal ${ }^{3}$, D Howes ${ }^{4}$, Nikita Morar ${ }^{5}$

\begin{abstract}
Radicular cysts most commonly occur in men in the third to fifth decades of life, presenting in the maxillary anterior region. They are of frequent occurrence but are usually asymptomatic and are often a serendipitous discovery when routine radiographs are taken. These cysts may present as multiple lesions affecting a number of teeth. Although the cysts usually heal after endodontic therapy alone, larger lesions may need additional treatment. When surgical enucleation in combination with endodontics is the treatment of choice, there is a possibility of inadvertent injury to adjacent teeth or structures. This case highlights an unusual presentation of symptomatic multilocular radicular cysts in the mandible of a female, subsequent endodontic treatment of the involved teeth and surgical enucleation of the cysts. Management of radicular cysts is case dependent and decisions should be based on medical and dental histories, the size and location of the cysts, and consideration of associated structures.
\end{abstract}

Key words: radicular cysts, multilocular, endodontic treatment

\section{INTRODUCTION}

Radicular cysts are amongst the most common cystic lesions of the jaw. They develop as a result of inflammatory processes within the root canal system of a tooth, leading to pulpal necrosis. Dental caries is the usual causative culprit. ${ }^{1}$ The cystic lining of the lesion arises from the epithelial cell rests of Malassez within the periodontal ligament. ${ }^{2}$ Most frequently radicular cysts are found at

1. Saidah Tootla: BChD (Western Cape), MSc (Wits), MPP (Wits). Department of Oral Rehabilitation, *

2. Vinayagie Premviyasa: $B O H$ (University of Durban Westville), BDS Wits), Registrar in Maxillo-facial Surgery (University of the Witwatersrand), ${ }^{*}$.

3. Veerasamy Yengopal: BChD (Western Cape), MChD (Stellenbosch), BSc Hon (Stellenbosch). Head of Department of Community Dentistry,

4. Dale Howes: BSC; BDS MDent (Wits); FCD; FICD. Head: Department of Oral Rehabilitation; *

5. Nikita Morar: Final Year Dental Student, ${ }^{\star}$

*School of Oral Health Sciences, University of the Witwatersrand

\section{Corresponding author}

Saidah Tootla:

Charlotte Maxeke Hospital, 7 York Rd, Parktown. Ward 385, Office 1.

Tel (w): +27 011488 4863. Tel (h): +27079500 3926.

E-mail: Saidah.tootla@wits.ac.za the apices of involved teeth, but may also occur along the roots in relation to lateral and accessory root canals. ${ }^{3}$ Radicular cysts account for about $52 \%$ to $68 \%$ of all the cysts found in the human jaw; ${ }^{4}$ they most commonly affect men in the third to fifth decades of life and usually present in the maxillary anterior region. According to Shear et al., they are usually asymptomatic and present with no visible extra-oral swellings. ${ }^{5}$

In most instances, radicular cysts are periapical lesions ranging from 0.5 to $1.5 \mathrm{~cm}$ in size, ${ }^{6}$ although, rarely, larger radicular cysts have been reported. ${ }^{7}$ Treatment options are determined by the size, extent and location of the lesion. Currently the standard approach is a conservative nonsurgical phase pr.9 $^{8,9}$ wich includes endodontic treatment, active non-surgical decompression, aspiration-irrigation, and the use of calcium hydroxide as an intra-canal medication. ${ }^{10}$

Although small radicular lesions can frequently heal with endodontic therapy alone, larger lesions may need additional treatment. In these larger lesions or in multiple radicular cystic lesions, surgical enucleation, marsupialisation or decompression in combination with endodontics, are the treatments of choice. ${ }^{11}$ The incidence of cystic lesions appears to be increasing in South Africa, ${ }^{5}$ and clinicians may be required to perform endodontic treatment on multiple teeth.

This case report highlights an unusual presentation and management of multiple radicular cysts, the subsequent root treatments of the involved teeth and surgical enucleation of the cysts.

\section{CASE REPORT}

\section{History}

A healthy female, 29-years of age, presented to the Charlotte Maxeke Hospital via referral from her local clinic. Relevant history included a motor vehicle accident in November of 1999 in which she had sustained multiple fractures and displacement of the following teeth: 11, 21, 24 and 45. As a result, the upper central incisors and left first premolar had been extracted at the local dental clinic (Figure 1).

In 2004 she noticed a swelling of the symphyseal area of the mandible and experienced a bad taste in her mouth. She returned to the local clinic where the dentist prescribed antibiotics, which apparently reduced the drainage of pus for a period of a few months. 




Figure 1: Anterior view

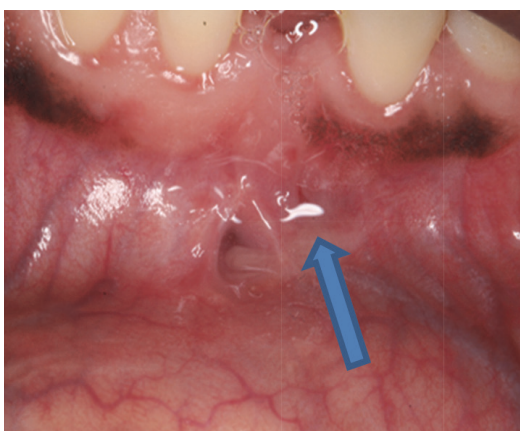

Figure 2: Draining fistula visible in the apica region of tooth 41 in the symphyseal region of the mandible

In September 2014 she returned to the local clinic complaining of a similar swelling which was progressively enlarging. The bad taste in her mouth was also becoming more pervasive. During this appointment, the 31 was extracted.

Two weeks later the patient returned to the local clinic complaining that the same swelling was causing discomfort despite the removal of the lower left central incisor (31). She was referred to the Maxillo-facial department of the University of the Witwatersrand, Johannesburg.

Her main complaint described a slow growing lesion in her lower jaw that caused a low grade, constant dull ache, and she often experienced a bad taste in her mouth (Figures 1-2).

Patient examination, diagnosis and management: (Figures 1-3)

\section{Examination}

The patient presented with a skeletal and dental Class 3 malocclusion complicated by an anterior open bite.

Extra-oral examination revealed a soft swelling of the mandible in the symphyseal area, extending bilaterally to the submandibular area. The right submandibular lymph nodes were palpable.

Intra-oral examination showed that multiple teeth were missing $(18,11,21,24,28,38,37,36,31,47)$ and retained roots of teeth 25,45 and 48 were observed. The maxillary molars were over-erupted, as a result of missing lower posterior teeth. The patient had only five functional occluding pairs of teeth [(16, 46); $(14,44) ;(13,43) ;(22,32)$; $(23,33)]$. Periodontal assessment found a plaque index of $25 \%$, a bleeding index of $5 \%$, but no probing depths of $4 \mathrm{~mm}$ or more. Teeth $41,43,31$ had Class 1 mobility according to Miller's classification. ${ }^{12}$
Palpation revealed a bilateral fluctuant and tender buccal swelling extending from the 35 to the 46 . A draining fistula was present on the midline region of the labial sulcus of the mandible, from which pus could be expressed (Figure 2).

Vitality tests were performed on all teeth, using the electrical pulp test, ethyl chloride and heated Gutta percha. Teeth 35,34,33,32,41,42,43,44,45,46 recorded negative responses and were confirmed non-vital. Tooth 41 was painful on vertical percussion.

\section{Radiographic assessment}

The radiographic assessment revealed large multilocular radiolucent lesions in the mandible extending from the region of the 36 to the 46 . The lesions involved the apices of all mandibular teeth, excluding the 48. The radiolucencies appeared well-circumscribed and a widening of the periodontal ligament space was noted on the 46 , the root rest of the 45, on 44, 43, 42, 41and 32 . A radiolucency was also observed at the furcation region of the 46 .

\section{Treatment Plan}

A multidisciplinary treatment conference was held which included input from clinicians representing endodontics, prosthodontics, maxillofacial surgery and orthodontics.

The following treatment plan was formulated:

1. Extraction of the 46 and the retained roots 25, 45 and 48.

2. Endodontic therapy of the $44,43,42,41,32,33,34$, and 35.

3. A surgical phase which would include enucleation of the cysts and curettage of associated teeth.

4. Orthodontic correction of occlusal collapse after establishing healing of the cystic lesions

5. Definitive oral rehabilitation with appropriate prosthodontics. Endodontically treated teeth were to be restored conservatively and if necessary with appropriate posts and crowns. The treatment of choice for the edentulous areas involved fixed implant-supported prostheses. 


\section{Endodontic Management}

Endodontic treatment was performed on a single quadrant per visit under local anaesthesia (lignocaine, xylitox with adrenalin, $1.8 \mathrm{ml}$ ampule) and strict rubber dam isolation. The Zeiss microscope was used for magnification. Relevant teeth were accessed using a round tungsten carbide bur. After completely de-roofing the pulp chamber and identifying the orifice(s), an Endo $Z$ bur was used to flare the axial walls in order to gain straight line access. The coronal flaring step was completed using a single stainless steel X-Gates bur (Dentsply Sirona). The necrotic pulp tissue was extirpated using small size 8 and $10 \mathrm{~K}$-files. Patency was then achieved $1 \mathrm{~mm}$ beyond the radiographic apex using a size $8 \mathrm{~K}$-file. The sac-like cystic structures contained bloodfilled serous exudate and some drainage was established after periapical instrumentation by virtue of patency. The canals were copiously irrigated with $1 \%$ sodium hypochlorite $(\mathrm{NaOCl}), \mathrm{RC}$ Prep and with normal saline as a final rinse. Working length was established and was confirmed with a periapical radiograph and the ProPex Pixi Apex Locator (Dentsply Maillefer).

The ProTaper Next rotary system (Dentsply Sirona) was used to shape and clean the canals in the sequence advocated by the manufacturer. Irrigation was again carried out copiously using $1 \% \mathrm{NaOCl}$, instrumented with the assistance of RC Prep and a final saline rinse. The 33 was the only tooth which presented with a weeping canal after cleaning and shaping. It was treated by placing calcium hydroxide as intracanal medicament for a period of one week. Once all the criteria for obturation were fulfilled, the teeth were obturated with the ProTaper single cone obturation materials, one $\mathrm{mm}$ short of the radiographic apex. Composite restorations were placed on the respective teeth as an interim measure to establish coronal seals.

\section{Surgical Phase}

The lesions were accessed via an intra-oral vestibular incision and a bony window was created on the labial surface of the mandible. The cysts were enucleated and the bone and apices of the endodontically treated teeth were debrided. The cavity was irrigated with saline and the soft tissues closed with 3.0 chromic sutures.

The specimens were sent for histopathologic diagnosis who confirmed the initial diagnosis of radicular cyst. The cystic cavity was shown to be lined by an inner stratified squamous epithelium with an outer granulation tissue showing chronic inflammatory cell infiltration and a few blood vessels.

\section{RESULTS}

At an 8-month follow-up visit the patient reported that the bad taste in her mouth had disappeared. The lesions had reduced in size and she no longer experienced discomfort (Figure 4). The root canal treatments were confirmed successful by virtue of the fact that pain was eradicated, and that the fistula had disappeared. Clinically and radiographically the lesion had decreased in size. ${ }^{13}$

The patient was referred for definitive treatment to the multidisciplinary team. At an 18-month follow-up visit, the lesion showed progressive reduction in size and all symptoms had completely disappeared.

\section{DISCUSSION}

Radicular cysts are inflammatory in nature and usually arise within a periapical granuloma resulting from the necrotic pulp of a permanent tooth. ${ }^{4,14}$ The current case is a rare presentation of large multiple cystic lesions occurring in the mandible of a 29-year old female patient as a consequence of trauma sustained to the lower jaw. Krishnamurthy et al. reported on a similar case of a radicular cyst masquerading as a multilocular radiolucency in the mandible, subsequent to trauma. ${ }^{15}$ However, the patient discussed in that study was a male in his early fifties. In 2012 Naspur et al. presented a rare case of a mandibular radicular cyst in a nine year old boy. The lesion demonstrated an unusual bilocular radiographic appearance along with expansion of the lingual cortex. ${ }^{16}$

The accumulation of dentinal and pulpal debris in the apical region is a common event in endodontic procedures and can cause blockage of root canals. This can be avoided by establishing initial apical patency, adequate irrigation and the filling technique. ${ }^{17,18}$ In this case study, patency was established $1 \mathrm{~mm}$ beyond the apex for the following reasons: the extent of penetration debrides the apical area, establishes drainage, relieves pressure and thereby provides decompression of the periapical lesion. ${ }^{19,20}$ It has been surmised that if drainage from infected root canals ceases, fibroblasts begin to proliferate in the apical region and collagen is deposited. The proliferation of fibroblasts compresses the capillary network causing starvation and degeneration of the epithelial cells, which will ultimately be engulfed by the macrophages..$^{19,20}$ According to Bender there is no scientifically-based evidence to support this assumption. ${ }^{21}$ However in the case presented, patency was indeed established to help eliminate micro-organisms and debris from the apical area. ${ }^{20,21}$ Furthermore, cyst resolution was also facilitated through the relief of cystic pressure. ${ }^{22}$

The significance of lesion size on healing has been researched in several studies. ${ }^{23,24}$ The treatment protocols implemented in these studies were dependent on the size and extent of the lesion and its relationship to adjacent teeth and structures. If the lesion was discreet in size, then most clinicians opted for a conservative treatment option by means of endodontic therapy. ${ }^{25,1}$ Sjogren et al found no significant difference in the healing rate between different sized lesions. ${ }^{23}$ According to Rees, large cyst-like peri-radicular lesions could be treated by non-surgical endodontic therapy. ${ }^{26}$ However other authors have stated that, in large or multiple connected lesions, endodontic treatment alone was not sufficient. Management should also include adjunctive techniques such as decompression, marsupialization or enucleation of the cyst. ${ }^{27,28}$

The treatment protocol at Maxillo-facial department of the University of the Witwatersrand, Johannesburg, for small radicular cysts, is endodontic treatment only and re-evaluation over time. However, larger lesions or multiple lesions may require a joint endodontic and surgical approach. To date, there are no established protocols for radicular cysts. The treatment of each lesion is dependent on its individual characteristics. The multidisciplinary management of this case is consistent with the literature reports on cases when patients were treated for multiple and large cysts. 


\section{CONCLUSION}

This is a clinical case report of large multilocular radicular cysts treated successfully by endodontic therapy, and surgical enucleation and debridement of the associated cystic lesions. The patient was referred to a multidisciplinary team for definitive oral rehabilitation after healing was initiated.

\section{References}

1. Bonder L. Cystic lesions of the jaws in children. Int $\mathrm{J}$ Pediat Otorhinolaryngol. 2002; 62:25-9 .

2. Shear M. Cysts of the Oral Regions. 3rd ed. Boston: Wright; 1992. Radicular and residual cysts; pp. 136-62.

3. Narula H, Ahuja B, Baliga RYS, Munshi AK. Conservative nonsurgical management of an infected radicular cyst. Contemp Clin Dent. 2011; 2(4): 368-71.

4. Nair PN. Review New perspectives on radicular cysts: Do they heal? Int Endod J. 1998; 31:155-60.

5. Shear M, Speight P. Cysts of the Oral and Maxillofacial Regions. 4th Ed. Singapore: Blackwell; 2007. pp.1: 24.

6. McNicholas S, Torabinejad M, Blankenship J, Bakland L. The concentration of prostaglandin E2 in human periapical lesions. J Endod 1991; 17:97-100.

7. Nilesh S Kadam, Ida De Noronha De Ataide, Phani Raghava, Marina Fernandes, Ruby Hede, Management of large radicular cyst by conservative surgical approach: A case report. J Clin Diagn Res. 2014; 8(2): 239-41.

8. Santos Soares SM, Brito-Júnior M, de Souza FK, Zastrow EV, Cunha CO, Silveira FF, Nunes E, César CA, Glória JC, Soares JA Management of cyst-like periapical lesions by orthograde decompression and long-term calcium hydroxide/ chlorhexidine intracanal dressing: A case series. J Endod. 2016;42(7):1135-41. doi: 10.1016/j.joen.2016.04.021.

9. Dwivedi S, Dwivedi CD, Chaturvedi TP, Baranwal HC. Management of a large radicular cyst: A non-surgical endodontic approach. Saudi Endodontic Journal. 2014;: 3(4): 145-8.

10. Sood N, Maheshwari N, Gothi R, Sood N. Treatment of large periapical cyst like lesion: A non-invasive approach: A report of two cases. Int J Clin Pediatr Dent. 2015; 8 (2); 133-7.

11. Balaji Tandri S. Management of infected radicular cyst by surgical decompression. J Conserv Dent. 2010; 13(3): $159-61$.

12. Miller PD Jr. A classification of marginal issue recession. Int $\mathrm{J}$ Periodontics Restorative Dent 1985;5(2):8-13

13. Hansrani V. Assessing root canal fillings on a radiograph--an overview. Br Dent J. 2015 27;219(10):481-3. doi: 10.1038/ sj.bdj.2015.882

14. Ten Cate AR. The epithelial cell rests of Malassez and the genesis of the dental cyst. Oral Surg Oral Med Oral Pathol. 1972;34:956-64. [PubMed]

15. Krishnamurthy V, Haridas S, Garud M, Vahanwala S, Nayak CD, Pagare SS, Radicular cyst masquerading as a multilocular radiolucency. Quintessence Int. 2013 Jan;44(1):71-3.

16. Narsapur SA, Chinnanavar SN, Choudhari SA, Radicular cyst associated with deciduous molar: A report of a case with an unusual radiographic presentation. Indian Journal of Dental Research. 2012; 23 (4): 550-3

17. Bhaskar SN. Nonsurgical resolution of radicular cysts. Oral Surg Oral Med Oral Pathol. 1972;34:458-68. [PubMed]

18. Flanders DH. Endodontic patency. How to get it. How to keep it. Why it is so important. N Y State Dent J. 2002 ;68(3):30-2

19. Mohammadi Z, Jafarzadeh H, Shalavi S, Kinoshita Jl. Establishing apical patency: To be or not to be? J Contemp Dent Pract. 2017;18(4):326-9.

20. Soares JA, Brito-Júnior M, Silveira FF, Nunes E, Santos SM. Favourable response of an extensive periapical lesion to root canal treatment. J Oral Sci. 2008;50(1):107-11.

21. Bender IB. Commentary on General Bhaskar's hypothesis. Oral Surg Oral Med Oral Pathol. 1972;34:469-76. [PubMed]

22. Valois CR, Costa-Júnior ED. Periapical cyst repair after nonsurgical endodontic therapy--case report. Braz Dent J.
2005;16(3):254-8. Epub 2006 Jan 12

23. Sjogren U, Hagglund B, Sundqvist G, Wing K. Factors affecting the long-term results of endodontic treatment. $J$ Endod 1990; 14:498e504

24. Matsumoto T, Nagai T, Ida K, et al. Factors affecting successful prognosis of root canal treatment. J Endod 1987;13:239e42.

25. Michael MH, Gary LL. Conservative treatment of persistent peri-radicular lesions using aspiration and irrigation. J Endod. 1990;16:182-6. [PubMed]

26. Rees JS. Conservative management of a large maxillary cyst. Int Endod J. 1997;30:64-7. [PubMed: 9477796]

27. Neaverth EJ, Burg HA. Decompression of large periapical cystic lesions. J Endod. 1982;8:175-82. [PubMed]

28. Tandri SB. Management of infected radicular cyst by surgical decompression. J Conserv Dent. 2010 Jul-Sep; 13(3): 159161. doi: 10.4103/0972-0707.71651 PMCID: PMC2980615 